\title{
PROJETO PILHAGUDO: UMA ALTERNATIVA SUSTENTÁVEL PARA A DESTINAÇÃO DE PILHAS E BATERIAS NO MUNICÍPIO DE AGUDO/RS.
}

\author{
CARLOS RUDOLFO PAUL', CLÁUDIA BERNARDINI², JANETE VANDA DUMKE ${ }^{3}$. \\ 1 - Geógrafo, estagiário do Depto. de Meio Ambiente da Prefeitura de Agudo. Autor, carlosrpaul@hotmail.com \\ 2 - Bióloga, Fiscal Ambiental do Departamento de Meio Ambiente da Prefeitura de Agudo. Autora, \\ claudia.ambiente@hotmail.com, 3-Engenheira Florestal do Departamento de Meio Ambiente da Prefeitura de \\ Agudo. Autora, jane.floresta@hotmail.com
}

Palavras-chave: pilhas,impacto ambiental, reciclagem, projeto comunitário.

A problemática da destinação final de resíduos como pilhas e baterias está presente nos diálogos da sociedade que se preocupa com os impactos ambientais e na saúde provocados pela má destinação final desses resíduos. Legalmente, há previsão de que esses resíduos especiais deveriam retornar para seus fabricantes, garantindo que os mesmos dariam o destino adequado. No entanto o cumprimento da legislação vigente que prevê a logística reversa ainda é uma utopia e as conseqüências da poluição gerada por esses materiais continuam. Como forma de minimizar esses impactos, o Departamento de Meio Ambiente da Prefeitura de Agudo e o Lions Clube de Agudo formaram uma parceria e lançaram o projeto PILHAGUDO. O mesmo se consistiu na busca de parcerias para a coleta e pagamento da reciclagem das pilhas e baterias, bem como a distribuição de 32 Papa-Pilhas (frascos de vidro devidamente identificados) na zona urbana e rural do Município: 13 em escolas municipais, estaduais e particulares, 02 em postos de saúde, 04 em supermercados, 01 no sindicato dos trabalhadores rurais, 02 na Prefeitura e Secretaria de Obras, 01 na Biblioteca, 01 na APAE (Associação de Pais e Amigos de Excepcionais), 01 no Instituto Cultural Brasileiro Alemão e 07 em casas comerciais das localidades do interior de Agudo. 0 projeto foi lançado dia 30 de maio de 2011, durante a comemoração da Semana do Meio Ambiente de Agudo, e em um mês de realização já contabiliza mais de $300 \mathrm{Kg}$ de material coletado. A coleta interna no município é feita pelo Departamento de Meio Ambiente e pelo Lions Clube, e o envio para reciclagem é feito através da ABINEE (Associação Brasileira da Indústria Elétrica e Eletrônica), que possui pontos de coleta na cidade de Santa Maria, e que garante a logística da reciclagem para empresa certificada, da cidade de São Paulo/SP. Este projeto não tem prazo de finalização, sendo continuado e fornecendo à população uma alternativa para a destinação destes resíduos especiais.

\section{Introdução}

Em tempos modernos o uso da tecnologia em nossas vidas vem crescendo cada vez mais. 0 telefone celular, computadores portáteis, aparelhos sonoros, e muitos outros equipamentos vieram para facilitar a vida, tornando a mais prática. Segundo dados da ANATEL 2011 obtidos através da rede Globo de notícias, até o final do mês de agosto deste ano, existiam no Brasil 224 milhões de aparelhos celulares.

Isto nos chama a atenção para uma questão importante. Grande parte de todas estas inovações tecnológicas funciona a base de pilhas ou baterias. Estas podem ser classificadas 


\section{Revista Eletrônica em Gestão, Educação e Tecnologia Ambiental}

REGET/UFSM (e-ISSN: 2236-1170).

levando em conta seu formato, tamanho, sistema químico, se não abertas ou fechadas, removíveis ou fixas no aparelho. Podem ser divididas em primárias (one way ou pilhas descartáveis) e secundárias - baterias recarregáveis ou acumuladores, no entanto a grande preocupação quando se fala em pilhas e baterias é em relação aos metais pesados contidos nelas e sua má destinação final, podendo ocasionar danos à saúde e ao meio ambiente. Quando presentes em água ou no ar, muitos podem se tornar extremamente tóxicos, podendo assim se depositarem no ciclo geológico e biológico, incluindo a bioconcentração em plantas e animais e a incorporação na cadeia alimentar, principalmente, através da água e do solo, (FIRJAN, 2000; Günther, 1998 apud Reidler, 2002).

É com relação a isto que surge uma indagação, o que fazer com estes materiais? Dispô-los em aterros sanitários comuns não é o destino correto. Conforme o CONAMA (Conselho Nacional de Meio Ambiente), já existe uma determinação em suas resoluções 257 e 263 de que os fabricantes de pilhas e baterias disponibilizem pontos de coleta destes materiais a fim de que possam dar um destino adequado a estes resíduos.

A Lei Estadual n. 11.019/97 prevê que pilhas e baterias que contenham mercúrio metálico não possam ser depositadas no lixo comum e que os fabricantes desses produtos ou seus representantes comerciais devem exigir dos consumidores as pilhas e baterias usadas.

Posteriormente a lei 12.305 de agosto de 2010 vem para implementar diretrizes relativas à gestão integrada e ao gerenciamento dos resíduos sólidos, incluindo os perigosos. Ela reforça também o que já havia sido regulamentado pelas resoluções do CONAMA, através da logística reversa, onde o meio empresarial toma a sua responsabilidade a cerca das pilhas e baterias, dando a estas um reaproveitamento em seu ciclo ou outros ou ainda dando a estes dispositivos um destino ambientalmente adequado.

A problemática da destinação final de resíduos como pilhas e baterias está presente nos diálogos da sociedade que se preocupa com os impactos ambientais e na saúde provocados pela má destinação final desses resíduos. No entanto o cumprimento da legislação vigente que prevê a logística reversa ainda é uma utopia e as conseqüências da poluição gerada por esses materiais continuam. Com objetivo de criar uma logística que garanta à população agudense a possibilidade de destinar as pilhas e baterias para reciclagem, bem como ter garantia da destinação final desse material para empresas recicladoras, o Departamento de Meio Ambiente da Prefeitura de Agudo e o Lions Clube de Agudo formaram uma parceria e lançaram o projeto PILHAGUDO.

\section{Metodologia}

Considera-se a metodologia deste trabalho como sendo uma pesquisa aplicada, qualitativa, visto que busca informações para geração de conhecimento visando a solução de problemas concretos do cotidiano da população (SILVA e MENEZES, 2001). O público alvo são todos os cidadãos residentes no Município de Agudo/RS. 


\section{Resultados e Discussão}

Após pesquisa sobre a problemática ambiental e de saúde causada pela poluição por resíduos de pilhas e baterias, foi procurada uma solução concreta para a resolutividade do problema. Primeiramente foi feito contato com empresa especializada, participante do Projeto Participe \& Recicle. Isso garantiria a destinação correta do material coletado no município.

Posteriormente foram realizadas parcerias com 5 empresas locais (4 supermercados e 1 sindicato) para viabilizar o custeio financeiro do projeto, e no início do mês de junho de 2011 foram distribuídos 32 Papa-Pilhas (frascos de vidro devidamente identificados) na zona urbana e rural do Município.

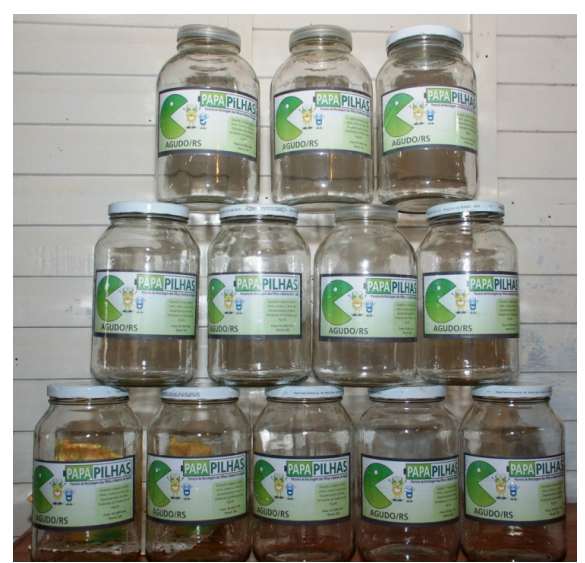

Figura 1. Papa-Pilhas que foram distribuídos Fonte: Erni Böck

A distribuição dos Papa-Pilhas aconteceu em 13 escolas municipais, estaduais e particulares, 2 em postos de saúde, 04 em supermercados, 1 no Sindicato dos Trabalhadores Rurais, 02 na Prefeitura e Secretaria de Obras, 1 na Biblioteca, 1 na APAE (Associação de Pais e Amigos de Excepcionais), 1 no Instituto Cultural Brasileiro Alemão e 7 em casas comerciais das localidades do interior de Agudo. Com essa abrangência todo Município, entendendo-se área urbana e rural, foram atingidos pelo projeto.

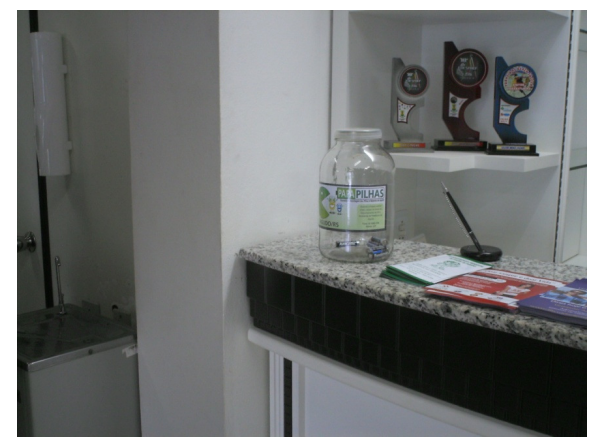

Figura 3. Papa-Pilha do hall de entrada da Prefeitura Municipal de Agudo Fonte: Depto. de Meio Ambiente

Próximo à data do envio da primeira carga de pilhas, que em seus dois meses iniciais (junho e julho de 2011) teve aproximadamente $300 \mathrm{Kg}$ de pilhas coletadas, descobriu-se que a ABINEE 
(Associação Brasileira da Indústria Elétrica e Eletrônica) possui um programa de recebimento de pilhas e baterias de forma gratuita (respeitando a lei da logística reversa) e tem um de seus pontos de coleta na cidade vizinha de Santa Maria/RS.

Foi através de uma das empresas parceiras do programa, que faz parte de uma grande rede de lojas e tem em sua sede um ponto de coleta da ABINEE, que foi encaminhada de forma gratuita os cerca de $300 \mathrm{Kg}$ de pilha coletados.

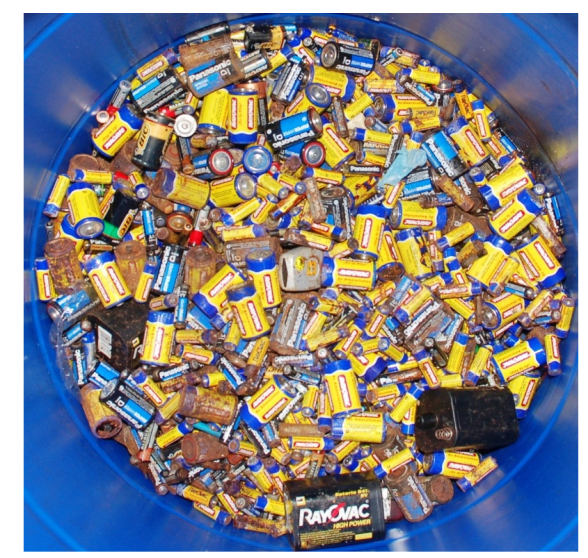

Figura 2. Pilhas já coletadas no PILHAGUDO Fonte: Erni Bock

O grande desafio é conseguir que o Município de Agudo seja também um ponto de referência para coleta pelo programa da ABINEE, Isso facilitaria a logística, valorizaria o projeto local e auxiliaria regionalmente os municípios que ainda não desenvolveram seus próprios programas de destinação final de pilhas e baterias.

\section{Conclusão}

A participação ativa da comunidade com pouco tempo de implementação do projeto, mostrou que a população vinha esperando por uma solução sustentável na destinação dos resíduos de pilhas e baterias. A satisfação pela implantação de um projeto continuado, com parcerias sólidas entre o poder público municipal, um clube de serviço local e empresas do município, bem como a adesão por parte da população nesta campanha, incentivam e provam a viabilidade do mesmo, bem como motivam para a construção de parcerias futuras frente à resolução de outros problemas ambientais.

\section{Bibliografia}

AMATO, F. País encerra agosto com 224 milhões de celulares, diz Anatel. Disponível em:

<http://g1.globo.com/tecnologia/noticia/2011/09/pais-encerra-agosto-com-224-milhoes-de-celulares-dizanatel.html. Acesso em 01 de novembro de 2011. 
BRASIL. Resolução CONAMA 257 de 30 de junho de 1999. Disponível em : <

http://www.mma.gov.br/port/conama/res/res99/res25799.html. Acesso em 13/08/2011.

BRASIL. Resolução CONAMA 263 de 12 de novembro de 1999. Disponível em:<http://www2.uca.es/grupinvest/cit/otros\%20\%20paises_archivos/Resoluc\%20263\%20Brasil.pdf. Acesso em 13/08/2011.

BRASIL. Lei Federal 12.305/2010. Institui a Política Nacional de Resíduos Sólidos. Disponível em: < http://www.planalto.gov.br/ccivil_03/_ato2007-2010/2010/lei/l12305.htm>. Acesso em: 10/09/2011.

COSTA, M.A.G.; COSTA, E.C. Poluição Ambiental: Herança para gerações futuras. Santa Maria: Orium, 2004.

GÜNTER, W.M.R; REIDLER, N.M.V. Impactos Ambientais e Sanitários causados por descarte inadequado de pilhas e baterias usadas. Disponível em:< http://www.ecolmeia.org.br/pilhasebaterias/impacto ambiental.pdf> Acesso em: 13/07/2011.

RIO GRANDE DO SUL. Lei Estadual n. 11.019/97. Dispõe sobre o descarte e destinação final de pilhas que contenham mercúrio metálico, lâmpadas fluorescentes, baterias de telefone celular e demais artefatos que contenham metais pesados no Estado do Rio Grande do Sul (Alterada pela Lei 11.187, de 7 de julho de 1998). Disponível em: < http://www.mp.rs.gov.br/ambiente/legislacao/id1979.htm. Acesso em $12 / 08 / 2011$.

SILVA, E.L.; MENEZES, E.M. Metodologia da pesquisa e elaboração de dissertação.Florianópolis: Laboratório de Ensino a Distância da UFSC, 2001. Disponível em: http://projetos.inf.ufsc.br/arquivos/Metodologia\%20da\%20Pesquisa\%203a\%20edicao.pdf> Acesso em: 19 out.2010. 